Research Article, Issue 2
Analytical Methods in Environmental Chemistry Journal
JMECJ
Journal home page: www.amecj.com/ir

\title{
Functionalized graphene-trimethoxyphenyl silane for toluene removal from workplace air by sorbent gas extraction method
}

\author{
Majid Bagheri Hosseinabadia, Shahnaz Timoori ${ }^{\mathrm{b}}$ and Ali Faghihi Zarandic,"
}

a School of Public Health, Shahroud University of Medical Sciences, Shahroud, Iran.

${ }^{b}$ Department of Environment and Natural Resources, Islamic Azad University, Science and Research Branch, Tehran, Iran.

${ }^{c}$ Occupational Health Engineering Department, School of Public Health, Kerman University of Medical Sciences, Kerman, Iran.

\begin{tabular}{|c|c|}
\hline A R T I C L E I N F O: & A B S T RACT \\
\hline Received 14 Feb 2019 & Inhalation exposure to toluene in the environment and workplace causes that \\
\hline Revised from 28 Apr 2019 & $\begin{array}{l}\text { some concerns about its adverse health effects on public and workers raise. So } \\
\text { the implementation of high-performance methods to control toluene emission in }\end{array}$ \\
\hline Accepted 20 May 2019 & industrial and environment settings is very important. Moreover, a new synthesized \\
\hline Available online 18 Jun 2019 & $\begin{array}{l}\text { sorbent based on functionalizing graphene with N-Phenyl-3-aminopropyl } \\
\text { trimethoxy silane }\left(\mathrm{G}-\mathrm{PhAPTMS}, \mathrm{C}_{12} \mathrm{H}_{21} \mathrm{NO}_{3} \mathrm{Si}\right) \text { was developed as a novel sorbent } \\
\text { for removal of toluene from air by sorbent gas extraction procedure (SGEP). By } \\
\text { proposed method, the removal efficiency of G-PhAPTMS was compared with }\end{array}$ \\
\hline--- & \\
\hline Keyw & concentrations, and the effects of parameters such as temperature $\left(10-90^{\circ} \mathrm{C}\right)$, flow \\
\hline Tolue & ng) were investigated. \\
\hline Chemical adsorption & ative \\
\hline Graphene & to $35^{\circ} \mathrm{C}$ and less than $250 \mathrm{~mL} \min ^{-1}(>95 \%)$. \\
\hline $\begin{array}{l}\text { N-Phenyl-3-aminopropyl } \\
\text { trimethoxy silane }\end{array}$ & $\begin{array}{l}\text { In optimized conditions, the amount of sorbent for toluene removal from air was } \\
\text { achieved more than } 10 \mathrm{mg} \text { of G-PhAPTMS. Finally, the results indicate that the }\end{array}$ \\
\hline $\begin{array}{l}\text { Sorbent gas extraction } \\
\text { procedure }\end{array}$ & $\begin{array}{l}\mathrm{G} \text {, and GO. Furthermore, functionalizing graphene with N-Phenyl-3-aminopropyl } \\
\text { trimethoxy silane improved the absorption of toluene due to chemical bonding } \\
(\pi-\pi \text { electron donor-acceptor) and introduced an environmentally friendly sorbent. }\end{array}$ \\
\hline
\end{tabular}

\section{Introduction}

Toluene is one of the well-known air contaminants and widely used as an organic solvent in various industries such as petroleum refining, shipping, rubber manufacturing, automobile repairing, and shoe manufacturing [1]. It is estimated that toluene is consumed about 2.3 million tons in worldwide annually [2]. Moreover, public and occupational exposure to toluene can occur through the inhalation of toluene fumes from cigarette smoking

\footnotetext{
* Corresponding Author: Ali Faghihi Zarandi

E-mail: alifaghihi60@yahoo.com

https://doi.org/10.24200/amecj.v2.i2.63
}

and vehicle emission [3]. In addition, it is likely to release from indoor sources such as paints, paint thinners, and adhesives [4].The studies have been shown that chronic exposure to toluene can cause a wide variety of health problems including neurotoxic effects (from headache and fatigue to narcosis with increasing exposure level) and mucosal irritation $[5,6]$. Because of the harmful effects of toluene, the implementation of highperformance methods to control toluene emission in industrial and environment settings is inevitable [7]. There are some different methods such as including adsorption, condensation, thermal 
oxidation, catalytic oxidation, photo catalytic oxidation and bio filtration that can be applied to reduce the concentration of toluene in air [8-11]. It seems that adsorption as a low operating cost and effective method can be used to remove toluene from air at low concentration[12, 13]. Adsorption is a process in which the molecules of pollutants are trapped at the surface of porous materials such as zeolites, silica gel and activated carbons by physical adsorption [14-16].

Among the different adsorbents, carbon adsorbing materials such as graphene oxide, activated carbons, carbon nanotubes, and porous carbon have demonstrated more advantage due to their low density, chemical stability and variety of structural forms [17-20]. The founding of new carbon materials is always one of the favorite subjects in the process of adsorption and sequestration [21]. Graphene, new two-dimensional carbon nanomaterial, as a new member of the carbon family with desirable properties such as low weight, small size, high surface area, and superior electrical, thermal and mechanical properties has attracted much attention [22-24]. The more advantage of graphene is the adsorption ability of chemicals with benzene rings like toluene through strong $\pi-\pi$ interaction $[25,26]$. In addition, some functional groups has turned graphene into an excellent adsorbent [27].

On the other hand, graphene has high theoretic surface area up to $2620 \mathrm{~m}^{2} \mathrm{~g}^{-1}$ that it become an ideal adsorption [28, 29]. Furthermore, graphene can be easily obtained from the cheap natural graphite in large scale [29, 30]. In this regard, the high adsorption capacity of graphene and its derivatives was confirmed for dyes [31], pharmaceutical antibiotics [32], heavy metals, and VOCs in water [33, 34]. However, the studies on toluene adsorption characteristics and behaviors onto graphene from air are limited [35].

In this study, toluene removed from air based on G-PhAPTMS by SGEP. The different experimental conditions such as mass, flow rate, and temperature were investigated and optimized. By proposed procedure, the chemically adsorption mechanism of toluene was achieved based on $\pi-\pi$ interaction between toluene and the surface of the G-PhAPTMS.

\section{Experimental procedure}

\subsection{Material and Instruments}

Toluene was purchased from Fluka (Germany) with purity above $99.5 \%$. In addition, standard gas was obtained by injecting a certain amount of toluene into a $10 \mathrm{ml}$ glass vial with PTFE cap to determine absorption capacity. In this study, helium and pure air were used as the dilution gas. Standard gas was prepared with a relative humidity of $32 \pm 5 \%$ for simulating the humidity in the workplace air. Thus, before filling the vial, the dilution gas was passed through deionized water. The concentrations of toluene in the standard gas were prepared from 9 to $75 \mathrm{mg} \mathrm{L}^{-1}$ (in batch system, high concentration up to $\left.400 \mathrm{mg} \mathrm{L}^{-1}\right)$.

In addition, a dynamic standard gas generation was designed to measure removal efficiency. This system consisted of impinger, adsorption tube, micro compressor, and sampling Tedlar bag (SKC Inc., USA). A certain amount of toluene was injected to the impinger, and then the dilution gas with a certain flow was passed through the adsorption tube. At the end of the system, unabsorbed toluene was collected into the Tedlar bag. The concentration of toluene in the Tedlar bag was measured by gas chromatography equipped with flame ionization detector (GC-FID) and air sample loop injection (Agilent GC, 7890A, FID, Netherland). Also, GCMS was used for validation toluene concentration in air.

The crystal structure studies of the solids were carried out by X-ray diffractions (PW 1840, Phillips X-ray diffractmeter, Netherland) with $\mathrm{Cu}-\mathrm{K}_{\alpha}$ radiation source. Raman spectroscopy was performed using an Almega Thermo Nicolet and $532 \mathrm{~nm}$ Ar-ion laser excitation source. The Fourier transform infrared (FT-IR) spectrum was recorded on Bruker IFS 88 spectrometer (Bruker Optik $\mathrm{GmbH}$, Ettlingen, Germany) with $\mathrm{KBr}$ pelleting method in the $4000-400 \mathrm{~cm}^{-1}$. The morphology of the sorbent was examined using scanning electron 
microscopy (SEM, Phillips, PW3710, Netherland) and transmission electron microscopy (TEM, CM30, Philips, Netherland).

\subsection{Synthesis of functionalized graphene with $\mathrm{N}$-Phenyl-3-aminopropyl trimethoxy silane}

Graphene (G) was prepared by our special CVD (chemical vapor deposition) method by an electrical furnace consisting of a quartz tube. The furnace heating tuned up to $1000{ }^{\circ} \mathrm{C}$ for $25 \mathrm{~min}$. The reaction between methane and hydrogen (4:1) was obtained. In order to pure grapheme without any metals, the product was stirred in $\mathrm{HCl}$ solution (ultra-trace) for about $20 \mathrm{~h}$. The sample was then washed repeatedly with ultra-pure water until the solution became neutral. The treated product was finally dried in oven at $120{ }^{\circ} \mathrm{C}$. For carboxylation process, $1 \mathrm{~g}$ of the as-prepared $\mathrm{G}$ was first mixed with a $200 \mathrm{~mL}$ mixture of concentrated $\mathrm{H}_{2} \mathrm{SO}_{4}$ and $\mathrm{HNO}_{3}(3: 1 \mathrm{v} / \mathrm{v})$ and stirred for $20 \mathrm{~min}$ at room temperature followed by sonication at $55{ }^{\circ} \mathrm{C}$ for 4 hours in an ultrasonic bath $(50 \mathrm{kHz}$ and $100 \mathrm{~W})$. After cooling to room temperature, the reaction mixture was diluted with $500 \mathrm{ml}$ of deionized water and then vacuum-filtered through a filter paper $(0.2$ $\mu \mathrm{m})$. Finally, G-COOH was dried in oven at 70 ${ }^{\circ} \mathrm{C}$. In order to the formation of the free hydroxyl group, $0.5 \mathrm{~g}$ of filtered $\mathrm{G}-\mathrm{COOH}$ was added to a methanolic solution of sodium borohydride. Then, the $\mathrm{G}$ bearing $-\mathrm{OH}$ group were allowed to disperse in xylene followed by addition of N-Phenyl-3aminopropyl trimethoxy silane (PhAPTMS) to synthesize functionalized $G$ in refluxing. After washing with xylene to remove the unreacted excess PhAPTMS, the product was dried for 10 $\mathrm{h}$ at $90{ }^{\circ} \mathrm{C}$ under reduced pressure. Morphology of the G-PhAPTMS was studied using scanning electron microscopy (SEM) and transmission electron microscopy (TEM). Graphite powder (5 g) and $\mathrm{NaNO}_{3}(2.5 \mathrm{~g})$ were mixed with $120 \mathrm{~mL}$ of concentrated $\mathrm{H}_{2} \mathrm{SO}_{4}$ and stirred for $30 \mathrm{~min}$ in an ice bath $\left(0-5{ }^{\circ} \mathrm{C}\right) . \mathrm{KMnO}_{4}(15 \mathrm{~g})$ was gradually added to the vigorously stirred suspension and the temperature of the mixture was kept to be below 15 ${ }^{\circ} \mathrm{C}$. The ice bath was then removed, and the mixture was stirred at $35{ }^{\circ} \mathrm{C}$ until it gradually became

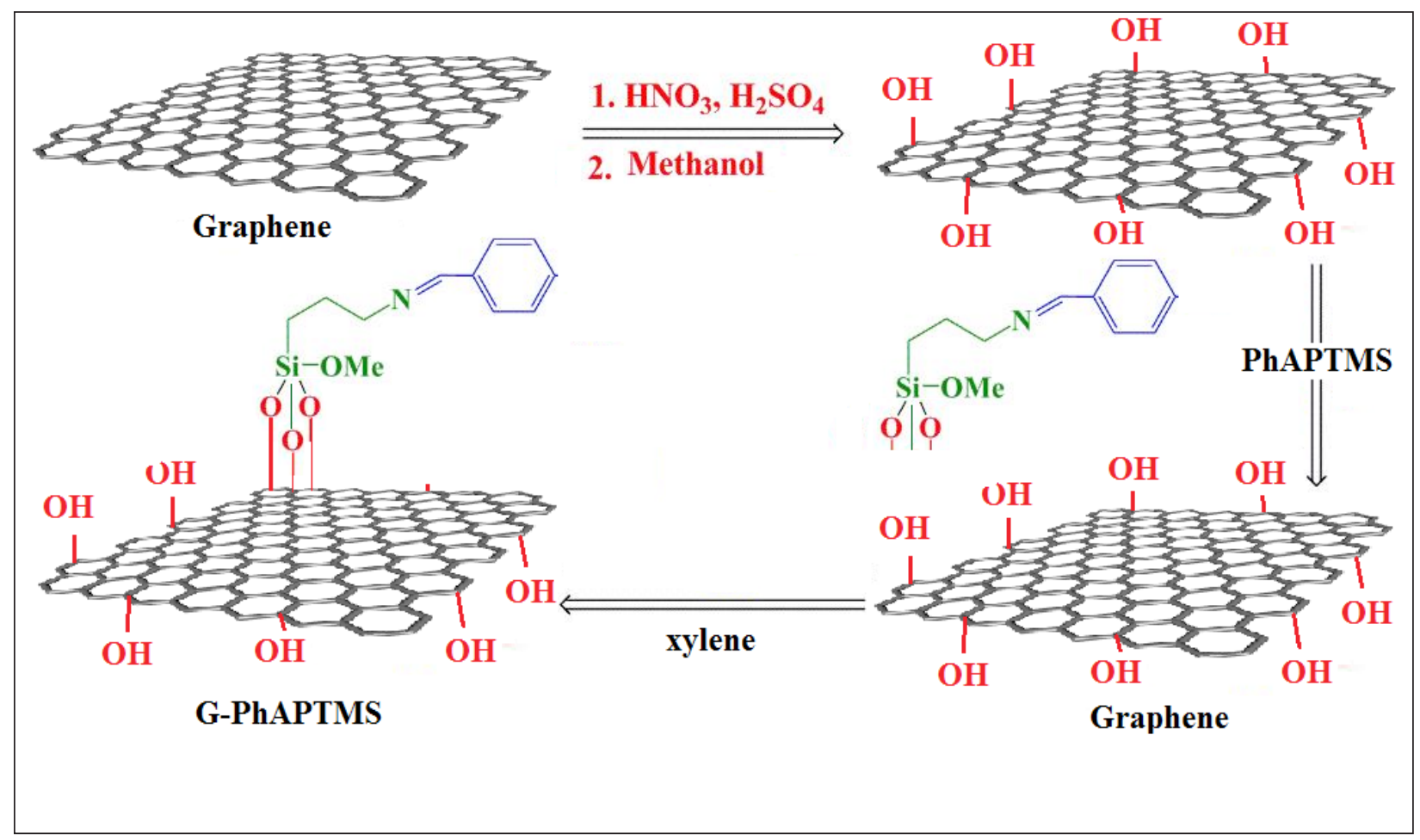

Scheme 1. Synthesis of functionalized graphene with N-Phenyl-3-aminopropyl trimethoxy silane 
brownish slurry, and then it was diluted slowly with $250 \mathrm{~mL}$ of water. The reaction temperature was rapidly increased to $98^{\circ} \mathrm{C}$ with effervescence, and the color changed to brown color. Later, $\mathrm{H}_{2} \mathrm{O}_{2}$ solution $(30 \%)$ was added to stop the oxidation process, and the color of the mixture changed to bright yellow, indicating fully oxidized graphite. The graphite oxide formed was washed by rinsing and centrifugation with diluted $\mathrm{HCl}$ solution and then repeatedly with deionized water until the filtrated solution became neutral. Graphene oxide nanosheets were obtained by ultra-sonication of the filtered graphite oxide suspension followed by centrifugation for $15 \mathrm{~min}$ at $3000 \mathrm{rpm}$ to remove any un-exfoliated graphite oxide (Scheme 1). Finally, it was air-dried at $60{ }^{\circ} \mathrm{C}$ for $12 \mathrm{~h}$. In this study, graphene oxide and activated carbon commercially were purchased from RIPI, Iran.

\subsection{General procedure}

Because the removal efficiency is highly affected by the amount of sorbent, the effects of amount of sorbents were studied in 1, 2, 4, 5, 10, 15, 20, 25 , and $30 \mathrm{mg}$ of different sorbents including G-PhAPTMS, G, GO and AC. The flow rate of the dilution gas was set from 50 to $500 \mathrm{ml} \mathrm{min}{ }^{-1}$. The effects of temperature on the absorption of toluene were investigated in different temperature from 10 to $90{ }^{\circ} \mathrm{C}$. The same concentration of standard gas of toluene was passed through the adsorption tube containing different amount of each sorbents in various thermal and flow rate conditions. The concentration of unabsorbed toluene collected in the Tedlar bag was analyzed by gas chromatography equipped with flame ionization detector. Removal efficiency was calculated as seen in Equation 1. The removal of toluene was evaluated in present of pure air in different flow rate by G-PhAPTMS, G, GO and $\mathrm{AC}$ as nanosorbents. In optimized conditions, the static and dynamic system was used by SGEP. The air was purified with electro air cleaner (EAC) and mixed with toluene in pilot. By proposed pilot, the pure air with and without toluene gas based on SGEP method was measured (5 times) by GC-FID and validated by GC-MS. The novel
G-PhAPTMS sorbent had chemical and physical adsorption between $\mathrm{G}$ and N-Phenyl with toluene, respectively. The mechanism of chemical adsorption was occurred based on $\pi-\pi$ interaction of N-Phenyl with toluene. Moreover, the G-PhAPTMS was more interaction than $\mathrm{G}$ for toluene removal from air. By new synthesis, $G$ was functioned by PhAPTMS and improved the compatibility between toluene and surface of sorbent in optimized conditions as compared to G, Go, and AC.

Removal Efficiency $=\mathrm{C}_{\text {in }}-\mathrm{C}_{\text {out }} / \mathrm{C}_{\text {in }} \times 100 \quad$ Eq 1

$\mathrm{C}_{\text {in }}\left(\mathrm{mg} \mathrm{L}^{-1}\right)$ and $\mathrm{C}_{\text {out }}\left(\mathrm{mg} \mathrm{L}^{-1}\right)$ were the concentration of toluene before and after adsorption respectively.

\section{Results and discussion}

Morphology of the G-PhAPTMS has been studied by SEM and TEM (Figure 1 and 2). After functionalizing of graphene with N-Phenyl-3aminopropyl trimethoxy silane, it seems that the graphene has much more active surface to absorb toluene.

\subsection{Effect of Temperature}

The removal efficiency of G-PhAPTMS, G, GO and $\mathrm{AC}$ in temperature from 10 to $90^{\circ} \mathrm{C}$ are shown in Figure 3. Functionalizing graphene could improve the properties of graphene in absorption of toluene from the air by increasing temperature. In addition, activated carbon had more removal efficiency rather than graphene oxide in the same conditions. The removal efficiency of G-PhAPTMS decreased

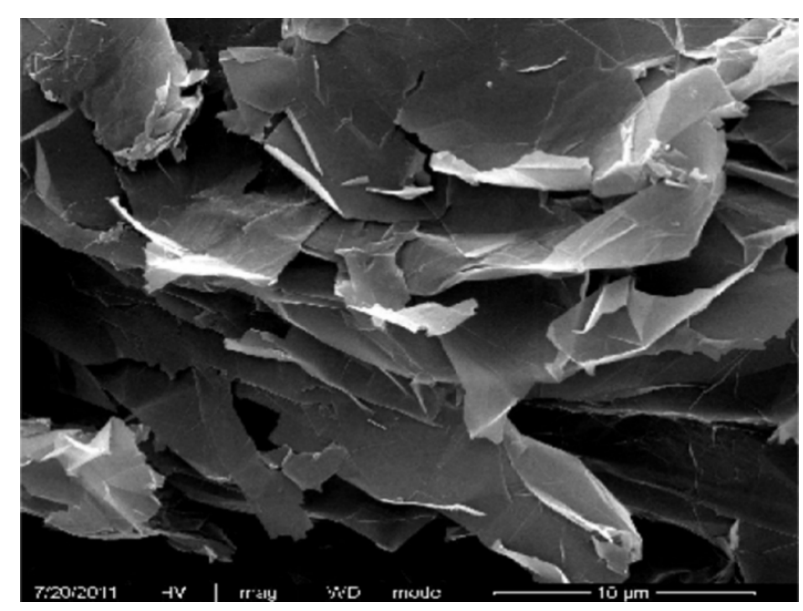

Fig. 1. SEM images of the G-PhAPTMS. 

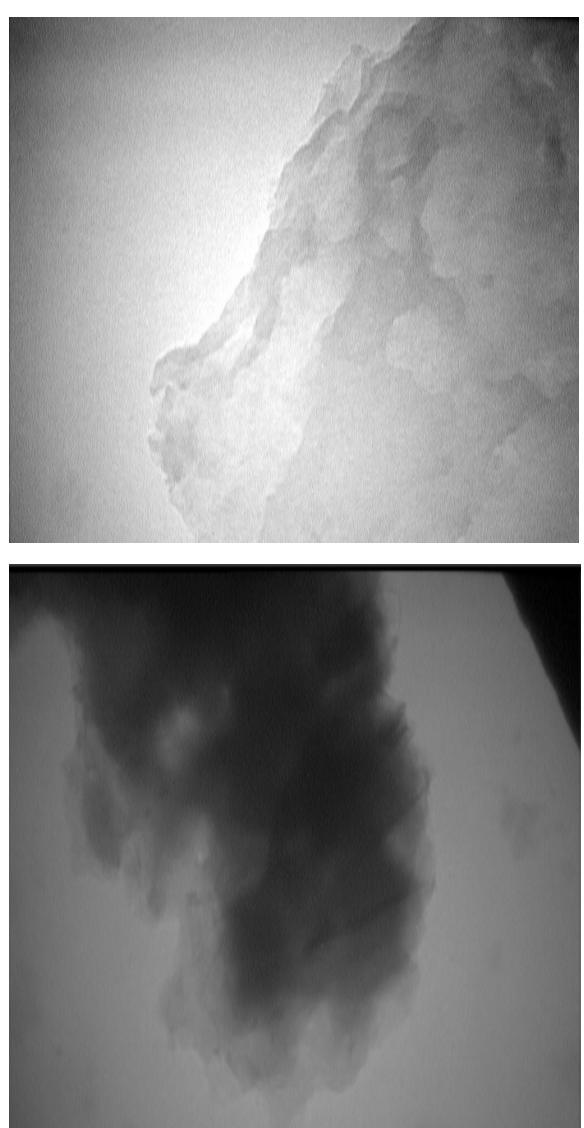

Fig. 2. TEM image of the G-PhAPTMS.

more than $50{ }^{\circ} \mathrm{C}$, while, the removal efficiency of AC and GO decreased sharply from $68 \%$ and $40 \%$ in $45^{\circ} \mathrm{C}$ to $5 \%$ and $2 \%$ in $90{ }^{\circ} \mathrm{C}$ respectively. Based on the results, the temperature can play a main role in removal efficiency of sorbents for toluene removal from air. By paying attention to previous studies, the removal efficiency with increasing temperature was reported in other studies [36]. For instance, Sone et al. (2008) reported that absorption of VOCs can be highly influenced by increasing temperature. They found that when temperature was increased from $50{ }^{\circ} \mathrm{C}$ to $80{ }^{\circ} \mathrm{C}$, the percentage of recovery of toluene decreased from 105.04 to 96.86 for charcoal [37]. Furthermore, it has been found out by Shih an Li in 2008 that lower temperature is a favorite condition for absorbing VOCs into the surface of carbon nanotube [38]. Overall, it can be argued the negative relation between increasing temperature and decreasing removal efficiency indicates that the sorption is an exothermic process, and decreasing temperature can improve the absorption properties of all investigated sorbents.

\subsection{Effect of flow rate}

The effect of flow rate on removal efficiency in $25{ }^{\circ} \mathrm{C}$ was investigated to optimize the flow rate conditions. The flow rate was set on 50 to $500 \mathrm{ml}$ $\min ^{-1}$ for all sorbents. The results are presented in Figure 4.

The removal efficiency of G-PhAPTMS, G, $\mathrm{GO}$, and $\mathrm{AC}$ decreased by increasing the flow rate, like temperature. The results showed, the more removal efficiency of G-PhAPTMS as compared to other sorbents, and the removal efficiency of G-PhAPTMS was decreased up to $62 \%$ in $500 \mathrm{ml}$

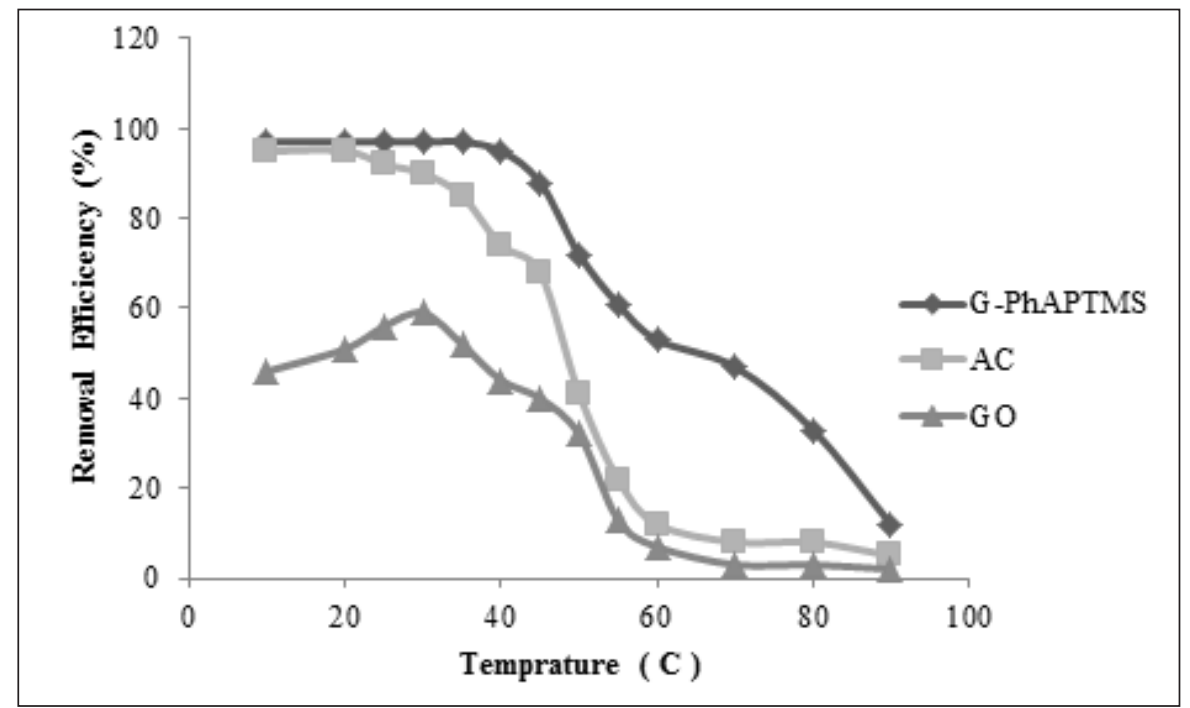

Fig. 3. the effects of temperature on removal efficiency of G-PhAPTMS, AC, and GO. 


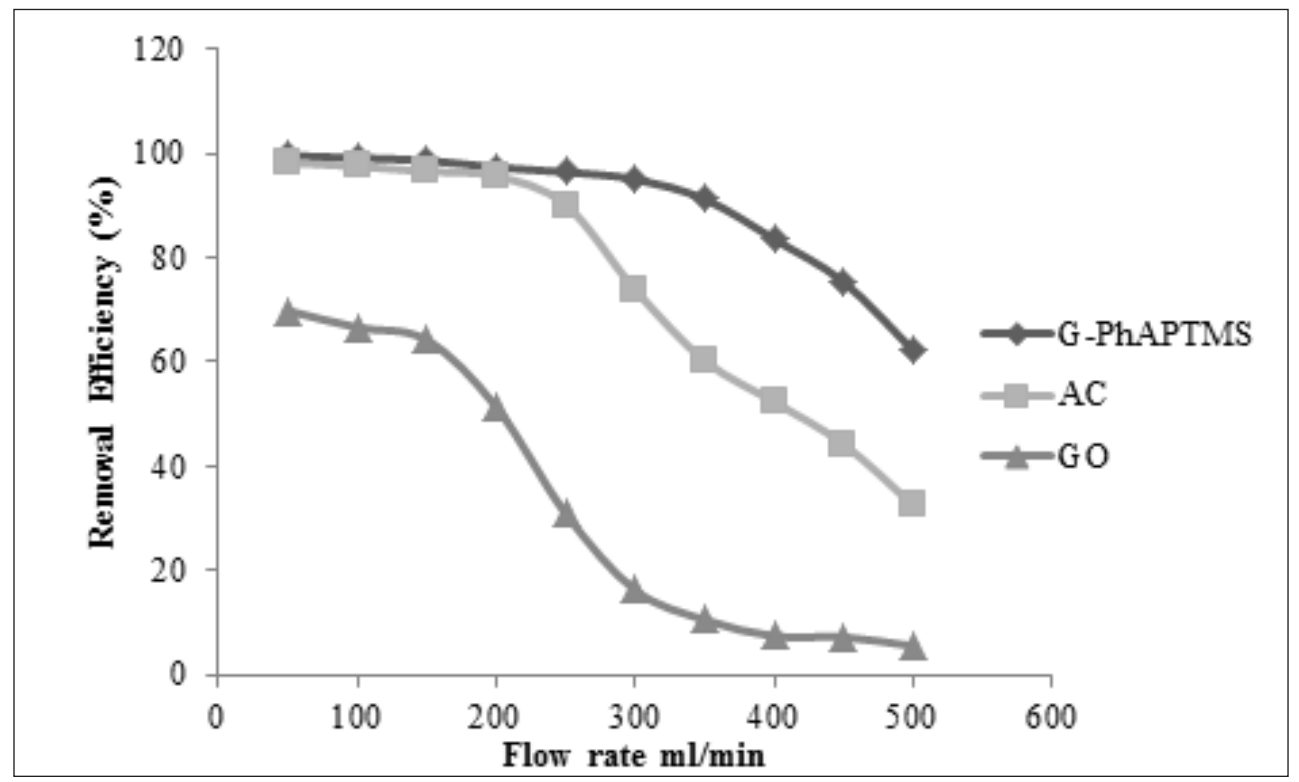

Fig. 4. the effects of flow rate on removal efficiency of G-PhAPTMS, AC, and GO.

$\min ^{-1}$. However, the removal efficiency of $\mathrm{AC}$ and $\mathrm{GO}$ in this flow rate was $32 \%$ and $5 \%$ respectively. Increasing the flow rate affected on the removal efficiency of all sorbents, but this effect was lower for G-PhAPTMS. Similarly, the impact of flow rate $\left(45,92\right.$ and $\left.184 \mathrm{ml} \mathrm{min}^{-1}\right)$ on the removal efficiencies of toluene, limonene and methyl ethyl ketone was investigated by Yao et al in 2009. Their results showed that removal efficiency was decreased from $79 \%$ to $21 \%$ by increasing the flow rate [39]. Moreover, declining removal efficiency of fluoride by increasing the flow rate from 20 to $30 \mathrm{ml} \mathrm{min}-1$ in activated alumina was reported by Ghorai and Pant [40]. The influence of flow rate on removal efficiency may be explained by reaction time. When the flow is high, the molecules of toluene have a little time to interact with the surface of absorbent, so they begin to escape from the end of the sorption tube [41].

\subsection{Effect of mass sorbent}

The amount of sorbent is another important parameter which was investigated in this study. The absorption tubes were loaded by different amounts of each absorbent from 1 to $30 \mathrm{mg}$ by proposed method. The temperature and flow rate were set on $25{ }^{\circ} \mathrm{C}$ and $200 \mathrm{ml} \mathrm{min}{ }^{-1}$. The results are shown in Figure 5.

The removal efficiency of toluene with G-PhAPTMS increased by increasing the amount of sorbent and reached the highest pint in $5 \mathrm{mg}$ of sorbent. In addition, the removal efficiencies of AC and GO followed the same pattern as the G-PhAPTMS, while reached the highest pint in 15 and $30 \mathrm{mg}$ of sorbents respectively. The GO had the lowest removal efficiency rather than the G-PhAPTMS, G, and AC for all amount of sorbent. The positive impact of amount of sorbent on removal efficiency was reported by Samarghandi et al (2017) in the removal of reactive red from distillated water. They found that the removal efficiency increased when the amount of active carbon and graphene increase from 0.2 to $4 \mathrm{~g} \mathrm{~L}^{-1}$ and 0.02 to $0.4 \mathrm{~g} \mathrm{~L}^{-1}$ respectively [42]. Higher amount of sorbent provides much more chance for the molecule of toluene to react with the available surface of sorbent. So, the removal efficiencies of sorbents increase effectively. Based on the results, the more active absorption sites of $\mathrm{g} \mathrm{L}^{-1}$ allow the molecules of toluene to absorb rapidly and 


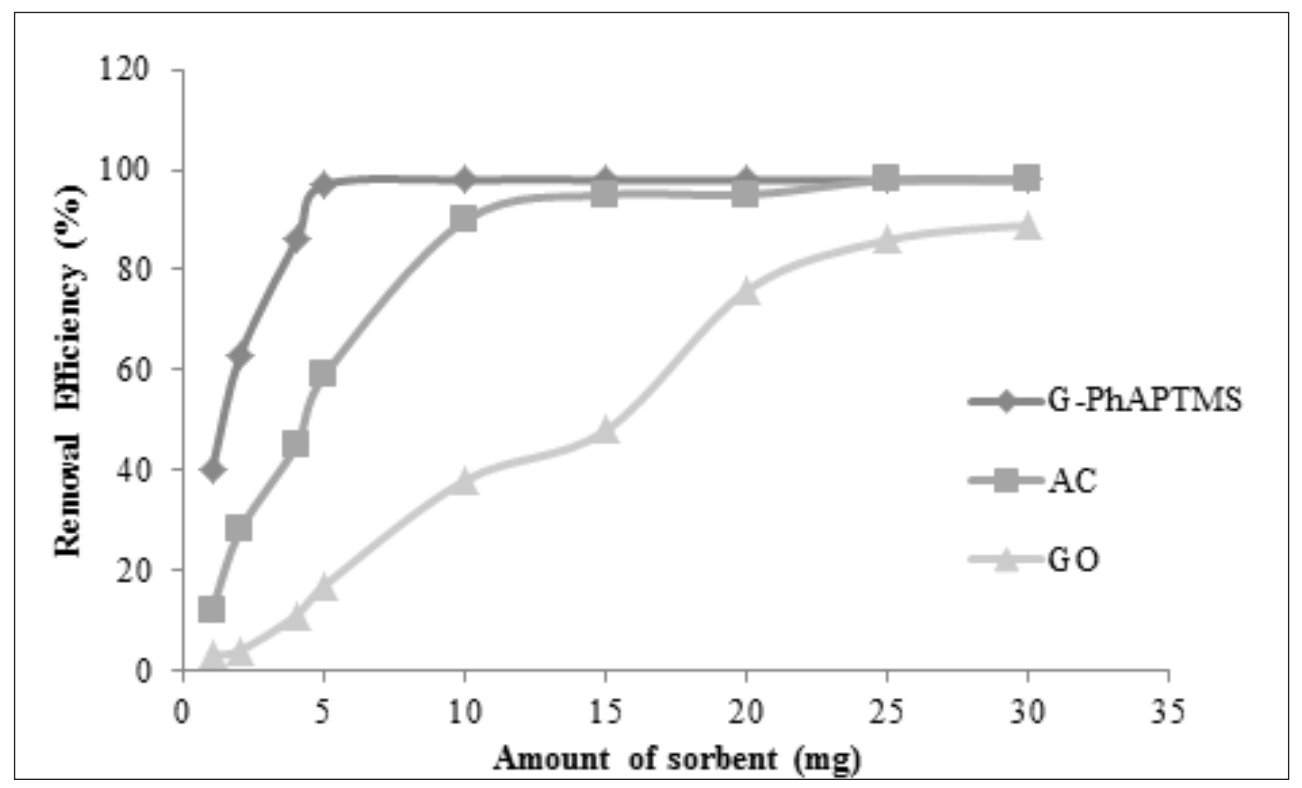

Fig. 5. the effects of amount of sorbent on removal efficiency of G-PhAPTMS, AC, and GO.

functionalizing graphene creates this opportunity that in the lower amount of sorbent, So we have maximum removal efficiency by G-PhAPTMS as compared with other sorbents. Repeatability of the sorbents was investigated in $25{ }^{\circ} \mathrm{C}, 200 \mathrm{ml} \mathrm{min}^{-1}$ and from 2 to $30 \mathrm{mg}$ of each sorbent (Figure 6). Each type of sorbent was used for twenty times and the mean of removal efficiencies were calculated.

The G-PhAPTMS had the highest removal efficiency for all investigated amount of sorbent compared with G, GO and AC sorbents after twenty times absorption and desorption. The mean of removal efficiency of AC experienced a downward pattern from 5 to $30 \mathrm{mg}$. Decreasing the removal efficiency for the GO happened from 20 $\mathrm{mg}$ to $30 \mathrm{mg}$ where the removal efficiency fell from 64 to $42 \%$. According to the results, functionalizing graphene with N-Phenyl-3-aminopropyl trimethoxy silane (G-PhAPTMS) can improve the absorption characteristics of graphene to absorb toluene from air.

\subsection{Validation}

The G-PhAPTMS was used as a novel and low-cost sorbent for removal of toluene vapor from air. By proposed method, a mixture of 5-100 ppm of toluene vapor in artificial air with argon gas as a carrier gas passed through sorbent (G-PhAPTMS) by a pump. The concentration of toluene in standard gas was validated by highly sensitive and accurate GC-MS instrument in different concentration before using by proposed method. Since standard reference material for toluene in air is not currently available, the spiked of validated toluene concentration in a bag (GC-MS, $50 \mathrm{ppm}$, bag $5 \mathrm{Li}, 0.2 \mathrm{~L} \mathrm{~min}^{-1}$ ) were prepared to demonstrate the reliability of the method by G-PhAPTMS. At optimum condition in one minute, $2.0 \mathrm{ppm}$ of toluene vapor in air was almost removed by G-PhAPTMS. The efficient recovery of spiked samples was reasonable and was confirmed using addition method, which it indicates the capability of proposed method for removal of toluene from air (Table 1).

\section{Conclusions}

In this study, different absorbents such as G-PhAPTMS, G, GO, and AC were used to remove toluene from air. The results showed that functionalizing graphene with N-Phenyl-3aminopropyl trimethoxy silane (G-PhAPTMS) 


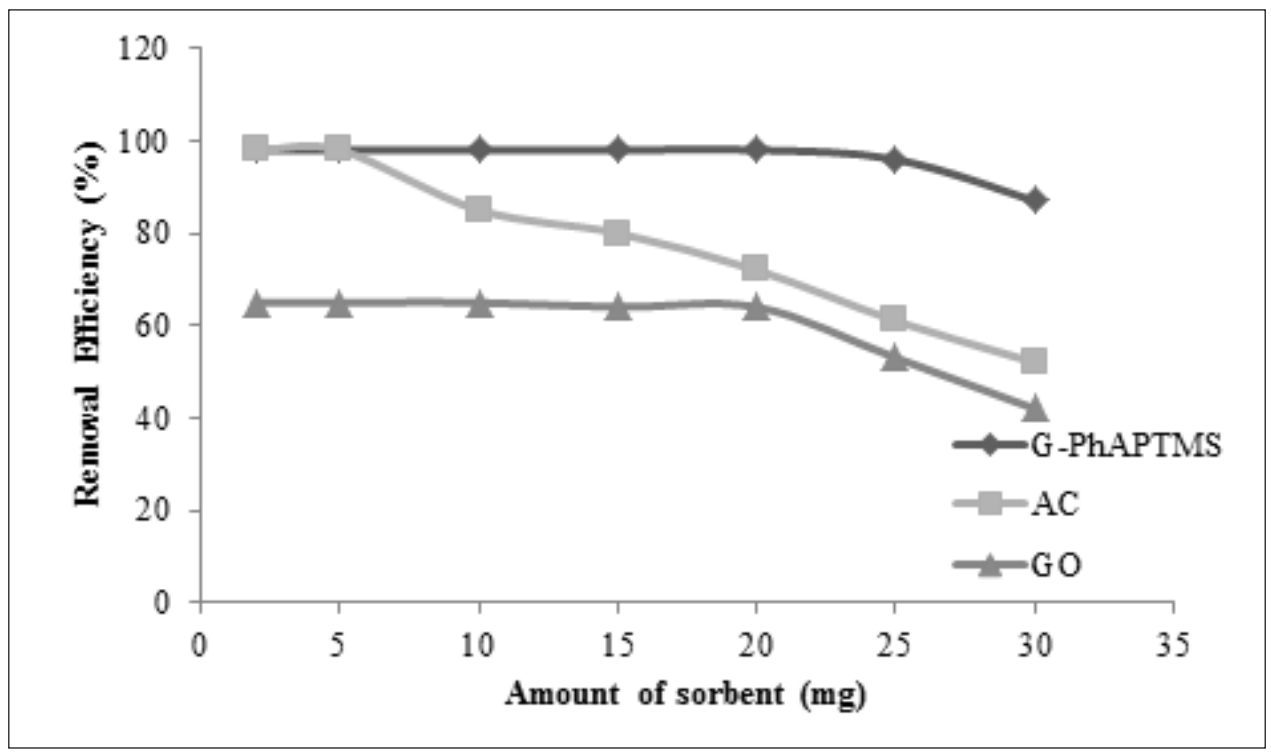

Fig. 6. The removal efficiency of different sorbents after using repeatedly.

Table 1: The recovery of G-PhAPTMS for removing toluene from air.

\begin{tabular}{lccc}
\hline Samples & Toluene in air $(\mathrm{ppm})^{*}$ & ${\text { Toluene in sorbent }(\mathrm{ppm})^{* *}}^{\text {Sorbent Recovery }(\%)}$ \\
\hline Sample A & $2.63 \pm 0.07$ & $2.57 \pm 0.11$ & 97.7 \\
\hline Sample B & $6.89 \pm 0.14$ & $6.48 \pm 0.21$ & 94 \\
\hline Sample C & $10.72 \pm 0.19$ & $10.51 \pm 0.32$ & 98 \\
\hline Sample D & $14.08 \pm 0.34$ & $13.52 \pm 0.84$ & 96 \\
\hline Sample E & $18.73 \pm 0.17$ & $17.35 \pm 0.28$ & 92.6 \\
\hline
\end{tabular}

* Initial concentration in standard gas

** Measured concentration in sorbent

promotes the removal efficiency of graphene by chemical bonding as $\pi-\pi$ electron donor-acceptor. Furthermore, increasing temperature and flow rate have negative effects of the removal efficiency of all sorbents, but the results of G-PhAPTMS showed high removal efficiency of toluene compared to the $\mathrm{AC}, \mathrm{G}$, and GO. The amount of sorbent was another parameter which was investigated. In optimized conditions, the amount of sorbent for the G-PhAPTMS, AC, and the GO were obtained 5,5 , and $30 \mathrm{mg}$ respectively. This result shows that the G-PhAPTMS has many more available active sites for absorption of toluene. By lower amount of G-PhAPTMS, high removal efficiency was achieved more than $95 \%$ by interaction between toluene and N-Ph. The results of repeatability of sorbents also indicate that functionalizing graphene with N-Phenyl-3-aminopropyl trimethoxy silane allows graphene to be used repeatedly, and it can be introduced as an environmentally friendly sorbent.

\section{References}

[1] S.K. Lim, H.S. Shin, K.S. Yoon, Kwack SJ, Um YM, Hyeon JH, et al. Risk assessment of volatile organic compounds benzene, toluene, ethylbenzene, and xylene (BTEX) in consumer products, J. Toxicol. 
Environ. Health, 77 (2014) 22-24.

[2] F. Yavari, C. Van, M.A. Nistsche, Effect of acute exposure to toluene on cortical excitability, neuroplasticity, and motor learning in healthy humans, Arch. Toxicol., 92 (2018) 3149-3162.

[3] P. Baltrènas, E. Baltrènaitè, V. Šerevičienè, P. Pereira, Atmospheric BTEX concentrations in the vicinity of the crude oil refinery of the Baltic region. Environmental monitoring and assessment, 182 (2011) 17-24.

[4] J. Taylor, M. Fay, R.L. Williams, S.B. Wilbur, P.R. McClure, K. Zaccaria, Toxicological profile for toluene, Stacks Cdc. Gov., 8 (2017) 1-62.

[5] F. Yavari, C. van Thriel, M.A. Nitsche, M.F. Kuo, Effect of acute exposure to toluene on cortical excitability, neuroplasticity, and motor learning in healthy humans, Arch. toxicol., 92 (2018) 3149-62.

[6] D. Deschamps, C. Geraud, S. Dally, Cognitive functions in workers exposed to toluene: evaluation at least 48 hours after removal from exposure, Int. Arch. Occup. Environ. Health, 74 (2001) 285-288.

[7] A. Romero-Anaya, M. Lillo-Ródenas, A. LinaresSolano, Spherical activated carbons for low concentration toluene adsorption, Carbon, 48 (2010) 53-59.

[8] M. Lillo-Ródenas, J. Carratalá-Abril, D. CazorlaAmorós, A. Linares-Solano, Usefulness of chemically activated anthracite for the abatement of VOC at low concentrations. Fuel. Process. Technol., 77 (2002) 331-6.

[9] L. Van De Beld, M.G. Bijl, A. Reinders, B. Van Der Werf, K. Westerterp, The catalytic oxidation of organic contaminants in a packed bed reactor, Chem. eng. sci., 49 (1994) 61-73.

[10] N. Bouazza, M. Lillo-Ródenas, A. Linares-Solano, Photocatalytic activity of $\mathrm{TiO} 2$-based materials for the oxidation of propene and benzene at low concentration in presence of humidity, Appl. Catal. B, 84 (2008) 691-8.

[11] C. Hort, S. Gracy, V. Platel, L. Moynault, Evaluation of sewage sludge and yard waste compost as a biofilter media for the removal of ammonia and volatile organic sulfur compounds (VOSCs), Chem. Eng. J., 152 (2009) 44-53.

[12] A.J. Fletcher, Y .Yüzak, K.M. Thomas, Adsorption and desorption kinetics for hydrophilic and hydrophobic vapors on activated carbon, Carbon, 44 (2006) 989-1004.
[13] J.H. Yun, K.Y. Hwang, D.K. Choi, Adsorption of benzene and toluene vapors on activated carbon fiber at 298, 323, and 348 K, J. Chem. Eng. Data, 43 (1998) 843-5.

[14] Q. Hu, J.J. Li, Z.P. Hao, L.D. Li, S.Z. Qiao, Dynamic adsorption of volatile organic compounds on organofunctionalized SBA-15 materials, Chem. eng. J, 149 (2009) 281-8.

[15] M. Lillo-Ródenas, D. Cazorla-Amorós, A. LinaresSolano, Behaviour of activated carbons with different pore size distributions and surface oxygen groups for benzene and toluene adsorption at low concentrations, Carbon, 43 (2005) 1758-67.

[16] A. Fuertes, G. Marban, D. Nevskaia Adsorption of volatile organic compounds by means of activated carbon fibre-based monoliths, Carbon, 41 (2003) 87-96.

[17] A. Dhaouadi, L. Monser, N. Adhoum, Removal of rotenone insecticide by adsorption onto chemically modified activated carbons, J. hazad. mate, 181 (2010) 692-9.

[18] M. Seredych, T.J. Bandosz, Adsorption of ammonia on graphite oxide/Al 13 composites. Colloids and Surfaces A, 353 (2010) 30-6.

[19] A. Silvestre-Albero, J. Ramos-Fernández, Martínez-Escandell M, Sepúlveda-Escribano A, Silvestre-Albero J, Rodríguez-Reinoso F. High saturation capacity of activated carbons prepared from mesophase pitch in the removal of volatile organic compounds, Carbon , 48 (2010) 48-56.

[20] L. Wang, D. Zhu, L. Duan, W. Chen, Adsorption of single-ringed $\mathrm{N}$-and S-heterocyclic aromatics on carbon nanotubes, Carbon, 48 (2010) 3906-3915.

[21] T. Wu, X. Cai, S. Tan, H. Li, J. Liu, W. Yang, Adsorption characteristics of acrylonitrile, p-toluenesulfonic acid, 1-naphthalenesulfonic acid and methyl blue on graphene in aqueous solutions, Chem. Eng. J., 173 (2011) 144-149.

[22] X. Huang, X. Qi, F. Boey, H. Zhang, Graphenebased composites, Chem. Soc. Rev., 41(2012) 66686.

[23] J.C. Meyer, A.K. Geim, M. Katsnelson, K. Novoselov, T. Booth, Roth S. The structure of suspended graphene sheets, Nature, 446(2007)603.

[24] H. Wang, X. Yuan, Y. Wu, H. Huang, X. Peng, G. Zeng, et al. Graphene-based materials: fabrication, characterization and application for 
the decontamination of wastewater and wastegas and hydrogen storage/generation, Adv. colloi. d interface. sci., 195 (2013)19-40.

[25] X. Cai, S. Tan, M. Lin, A. Xie, W. Mai, X. Zhang, et al. Synergistic antibacterial brilliant blue/ reduced graphene oxide/quaternary phosphonium salt composite with excellent water solubility and specific targeting capability, Langmu., 27(2011)2835.

[26] W. Wang, T. Sun, Y. Zhang, Y.B. Wang, Substituent effects in the $\pi \cdots \pi$ interaction between graphene and benzene: An indication for the noncovalent functionalization of graphene, Comput. Theor. Chem., 1046 (2014) 64-69.

[27] D. Gu, J.B. Fein, Adsorption of metals onto graphene oxide: Surface complexation modeling and linear free energy relationships, Colloid. Surf. A. Physicochem. Eng. Asp., 481 (2015) 319-27.

[28] M.J. Allen, V.C. Tung, R.B. Kaner, Honeycomb carbon: a review of graphene. Chemical reviews, 110 (2009) 132-45.

[29] S. Stankovich, D.A. Dikin, G.H. Dommett, K.M. Kohlhaas, E.J. Zimney, E.A. Stach, et al. Graphenebased composite materials. Natur, 442 (2006) 82-6.

[30] K. Zhang, V. Dwivedi, C. Chi, J. Wu, Graphene oxide/ferric hydroxide composites for efficient arsenate removal from drinking water, J. hazard. mater, 182 (2010) 162-8.

[31] S.T. Yang, S. Chen, Y. Chang, A. Cao, Y. Liu, H. Wang, Removal of methylene blue from aqueous solution by graphene oxide. Journal of colloid science, 359(2011)9-24.

[32] Y. Gao, Y. Li, L. Zhang, H. Huang, J. Hu, S.M. Shah, et al, Adsorption and removal of tetracycline antibiotics from aqueous solution by graphene oxide. Journal of Colloid Sci., 368 (2012) 540-6.

[33] G. Zhao, J. Li, X. Ren, C. Chen, X. Wang, Fewlayered graphene oxide nanosheets as superior sorbents for heavy metal ion pollution management. Environ sci. technol, 45 (2011) 54-62.

[34] G. Zhao, X. Ren, X. Gao, X. Tan, J. Li, C. Chen, et al, Removal of $\mathrm{Pb}$ (II) ions from aqueous solutions on few-layered graphene oxide nanosheets, Dalton Transactions, 40 (2011) 45-52.

[35] W. Wang, J. Yu, Q. Xiang, B. Cheng, Enhanced photocatalytic activity of hierarchical macro/ mesoporous TiO 2-graphene composites for photodegradation of acetone in air, Appl. Catal. B,
119 (2012) 9-16.

[36] M.B.H. Abadi, H. Shirkhanloo, J. Rakhtshah, Air pollution control: The evaluation of TerphApm@ MWCNTs as a novel heterogeneous sorbent for benzene removal from air by solid phase gas extraction, Arab. J. Chem., 11 (2018) 287-301.

[37] H. Sone, B. Fugetsu, T. Tsukada, M. Endo, Affinitybased elimination of aromatic VOCs by highly crystalline multi-walled carbon nanotubes, Talanta, 74(2008) 65-70.

[38] Y.h. Shih, M.s. Li, Adsorption of selected volatile organic vapors on multiwall carbon nanotubes. J. Hazard. Mater, 154 (2008) 8-21.

[39] M. Yao, Q. Zhang, D.W. Hand, D. Perram, R. Taylor, Adsorption and regeneration on activated carbon fiber cloth for volatile organic compounds at indoor concentration levels. J. Air. Waste. Manag. Assoc., 59 (2009) 31-6.

[40] S. Ghorai, K. Pant, Equilibrium, kinetics and breakthrough studies for adsorption of fluoride on activated alumina, Sep. Purif. Technol., 42 (2005) 65-71.

[41] N. Mohan, G. Kannan, S. Upendra, R. Subha, N. Kumar, Breakthrough of toluene vapours in granular activated carbon filled packed bed reactor. J. hazard. mater, 168 (2009) 77-81.

[42] M.R. Samarghandi, A. Poormohammadi, S. Shanesaz, K. Godini, Comparison Between the Performance of Activated Carbon and Graphene in Removal of Reactive Red 198, Avicenna, J. Environ. Health. Eng., 4 (2017) 17-23. 